УДК 323.2

\title{
Павел КАНЕВСКИЙ
}

\section{ТЕНДЕНЦИИ РАЗВИТИЯ ЛОББИЗМА В БРИТАНИИ}

\begin{abstract}
Аннотация. Статья посвящена комплексному анализу развития лоббизма в Великобритании в конце XX - начале XXI вв. Лоббизм является неотъемлемым элементом британского политического процесса, но при этом относительно немного известно о возможностях, которыми обладают группы интересов на процесс принятия решений. Взаимодействие групп интересов и представителей власти становится всё более разносторонним и многоуровневым. Автор ставит своей целью ревизию механизма лоббистской деятельности в Великобритании, анализирует процессы взаимодействия групп интересов и лоббистов с гражданской службой, квази-автономными неправительственными организациями, политическими партиями и парламентом, кабинетом министров и премьер-министром. Рассмотрена эволюция и современное состояние регулятивной среды лоббизма. Автор приходит к выводу, что тенденции развития лоббизма в Великобритании имеют двоякий характер. С одной стороны, группы интересов и представители власти заинтересованы в сохранении существующего механизма взаимодействия. Для партий и правительства поддержка групп интересов означает получение информации и ресурсов. Группы интересов, в свою очередь, заинтересованы в сохранении традиций политической открытости и постоянном доступе к органам власти. С другой стороны, постоянные скандалы, низкий уровень общественного доверия к лоббистам и снижающаяся легитимность партий вынуждают политиков и лоббистов искать способы регулирования отрасли с целью повышения прозрачности принимаемых решений. Вопреки пересмотру кодексов поведения и принятию первого в истории Британии закона о лоббизме, бо́льшая часть реальных лоббистских отношений продолжает оставаться в тени. Таким образом, лоббизм в Великобритании развивается в условиях противоречий между необходимостью поддержания свободы взаимодействия групп интересов и органов власти и прозрачностью политического процесса.
\end{abstract}

Ключевые слова: лоббизм, группы интересов, политика в Великобритании, гражданская служба, британский парламент.

(C) Каневский Павел Сергеевич - кандидат политических наук, доцент кафедры политологии и социологии политических процессов социологического факультета МГУ им. М.В. Ломоносова. Адрес: 119991, Россия, Москва, Ленинские горы, д. 1. E-mail: kanevskiy@ socio.msu.ru

DOI: http://dx.doi.org/10.15211/soveurope220196272 


\section{Роль лоббизма в британской политике}

Слова “лоббизм” и “лоббист” лишь в 1990-е гг. стали общеупотребимыми для описания процесса влияния групп интересов на органы власти в Великобритании, лоббизм имеет богатую историю в этой стране. К. Макграт указывает на то, что в британской прессе слова "лоббист" и “лоббизм" периодически упоминались в течение XIX-XX вв., и долгое время не предпринималось попыток научной систематизации данных явлений [McGrath, 2018: 228]. Когда Г. Уоттон впервые изучил деятельность групп интересов в Великобритании за 1750-1970 гг. на основе контентанализа парламентских документов, то обнаружилось, что первое официальное упоминание лоббизма относится только к 1913 г. Парламентская запись указывала на некоего Ч. Кента, который имел должность "парламентского лоббиста" [Wootton, 1975: 216-217], хотя очевидно, что реальная практика лоббизма существовала и до этого. В период между двумя мировыми войнами прошла первая волна профессионализации лоббизма, когда стали появляться консультанты, за плату предоставлявшие услугу продвижения интересов в органах власти. Первая лоббистская фирма Watney \& Powell была открыта в 1926 г. [White et al., 2009: 383]. Однако первый серьёзный всплеск общественного и научного интереса к лоббизму приходится на 1980-1990-е гг., когда вслед за неолиберальными реформами М. Тэтчер произошёл скачкообразный рост рынка лоббистских услуг.

Система групп интересов в Великобритании носит отчётливый плюралистический характер, что соответствует британской традиции низовой политической активности и сильного гражданского общества. Британское гражданское общество носит дисперсный и децентрализованный характер, предоставляя возможность влияния на политический процесс не только через институты представительства, прежде всего политические партии, но и посредством членства в различных групповых объединениях. По словам Л.Е. Ильичевой, “лоббизм в Великобритании считается столь же естественным институтом, как сам парламент" [Ильичева, 2014: 51]. Эксперты насчитывают более 7 тыс. организованных групп интересов в Великобритании, что более чем вдвое превышает показатель 1960 г. [Heywood, 2008: 127]. В их число входят деловые и торговые ассоциации, отдельные корпорации, профсоюзы и профессиональные ассоциации, церковные и благотворительные организации, исследовательские центры, некоммерческие образовательные, экологические организации, группы, выступающие за защиту прав человека, сокращение бедности, урегулирование международных конфликтов и пр. Кроме того, Великобритания идет по пути профессионализации лоббизма благодаря постоянно увеличивающемуся количеству компаний, оказывающих услуги политического консалтинга. В стране насчитывается около 3500-4000 профессиональных лоббистов, а финансовый оборот рынка услуг в данном секторе оценивается в 2 млрд ф. ст. [David-Barrett, 2015: 11] $]^{1}$. Это делает рынок лоббизма в Великобритании третьим по величине в мире после США и наднационального уровня в Евросоюзе.

\footnotetext{
${ }^{1}$ Introducing a statutory register of lobbyists. House of Commons. URL: https://publications.parliament.uk/pa/cm201213/cmselect/cmpolcon/153/153.pdf (дата обращения: 29.10.2018).
} 
Динамика института лоббизма в Великобритании характеризуется, прежде всего, высоким уровнем вовлечённости групп интересов в процесс принятия решений. Власть все больше зависит от экспертной информации и ресурсов, которыми обладают группы интересов. Согласно Ф. Уэйлеру и М. Брандли, “политикам не хватает времени, ресурсов и адекватной информации, чтобы быстро реагировать на происходящие изменения и принимать решения. Информация, предоставляемая группами интересов, восполняет нехватку экспертных знаний” [Weiler, Brandli, 2015: 747]. Брекзит отчётливо продемонстрировал, каким образом власть восполняла нехватку понимания будущих торговых соглашений, активно консультируясь с корпоративным сектором, а бизнес, таким образом, доносил своё видение проблем ${ }^{1}$. Ресурсы в обмен на влияние являются другим вектором встраивания групп интересов в политический процесс. Так, после кризиса 2008 г. правящая коалиция активно привлекала деловые круги к антикризисным проектам. Ярким примером стал проект "Мерлин", который предусматривал выделение 190 млрд ф. ст. среднему и малому бизнесу со стороны четырёх ведущих банков, а правительство в ответ отменило 50процентный налог на банковские бонусы [Громыко, Ананьева, 2014: 50-51].

Другая тенденция заключается в увеличении количества объектов лоббизма. Гражданская служба остаётся центральным звеном механизма лоббирования, но развитие непубличных органов власти, процедуры согласования и изменения решений в парламенте, финансирование избирательных кампаний, а также теневые отношения между лоббистами и официальными лицами делают этот механизм более дисперсным. Помимо этого, всё больше полномочий переходит от Вестминстера и Уайтхолла к исполнительным и законодательным органам власти в Шотландии, Уэльсе и Северной Ирландии. Учитывая стремление регионов к большей автономии, местные политики становятся всё более открытыми по отношению к группам интересов. Как пишут Б. Холден и К. Хокингс применительно к Шотландии, “новая, более открытая политика изначально была одной из главных задач автономизации Шотландии и группы интересов в целом оказались удовлетворены внедрением новых консультативных механизмов и упрощением доступа к местным политикам и высшим должностным лицам" [Holden, Hawkins, 2012: 254]. Однако вследствие постоянного роста индустрии лоббизма в Великобритании растёт запрос на создание более прозрачной регулятивной среды, что толкает политиков на ужесточение этических кодексов и законодательства.

\section{Гражданская служба и публичные органы власти}

Основная нагрузка на разработку законопроектов ложится на гражданскую службу, которая стала более открытой для внешнего влияния, несмотря на то, что большая часть контактов находится в тени. По словам Л. Зеттера, практически любая организация, вовлечённая в процесс лоббирования, “от крупной компании до небольшой благотворительной организации, добьётся поддержки от того или иного департамента в правительстве” [Zetter, 2008: 103]. Гражданская служба готовит для

1 Lobbyists: Brexit's Biggest Beneficiaries, Unlock Democracy, Spinwatch, 2018. URL: https://static1.squarespace.com/static/5525bbf5e4b026f75314c09b/t/5b9794400ebbe8b81e085a3 c/1536660551240/Lobbyists+-+Brexit\%27s+Biggest+Beneficiaries.pdf (дата обращения: 29.10.2018).

Современная Европа, 2019, №2 
правительства Зелёные и Белые книги - документы, которые ложатся в основу будущих законодательных проектов. Учитывая, что большинство решений начинают формулироваться именно в недрах гражданской службы, это делает её ключевой точкой входа для групп интересов. Роль посредников во взаимодействии между сложным механизмом гражданской службы и министрами играют специальные советники. В этическом кодексе специальных советников оговариваются ограничения, касающиеся занятий лоббистской деятельностью в течение двух лет после окончания службы ${ }^{1}$, однако рекомендации правительства разрешают советникам, равно как и всем гражданским служащим, контакты с лоббистами, если это отвечает интересам государства ${ }^{2}$.

В результате реформ, начатых М. Тэтчер, численность гражданских служащих упала до 400 тыс. в 2015 г. (по сравнению с 650 тыс. в 1979 г.) $)^{3}$. Тем не менее она продолжает оставаться центральным звеном механизма лоббирования. Реформы системы управления привели также к тому, что гражданская служба более не является монополистом в распределении государственных ресурсов, так как часть функций взяли на себя появившиеся в 1980-е гг. КВАНГО - квази-автономные неправительственные организации. Они формально не входят в структуру правительства, однако напрямую от него зависят, так как их создают, изменяют и расформировывают по решению министров, а финансируются они из государственно бюджета. По словам А.А. Ходырева, КВАНГО должны служить в качестве “инструмента разделения рисков в принятии управленческих решений между профильным министром и менеджером соответствующего КВАНГО, что преподносится как необходимая политико-административная мера в эпоху неуклонного усложнения социально-экономических задач правительства" [Ходырев, 2013: 528]. За последние годы такого рода организации значительно усилили свои позиции, особенно в бюджетной политике. Если в 2006 г. было 883 публичных органа власти, которые израсходовали почти 37 млрд ф. ст. ${ }^{4}$, то в 2016 г. насчитывалось более 450 КВАНГО, которые управляли частью расходов государственного бюджета в размере 195 млрд ф. ст 5 .

Постоянно увеличивающаяся роль КВАНГО сделала их объектом внимания со стороны групп интересов, особенно тех, которые зависят от распределения бюдже-

${ }^{1}$ Code of conduct for special advisers, Cabinet Office, 2016. URL:

https://assets.publishing.service.gov.uk/government/uploads/system/uploads/attachment_data/file 1579768/code-of-conduct-special-advisers-dec-2016.pdf (дата обращения: 29.10.2018).

${ }^{2}$ Guidance for civil servants: contact with lobbyists, 1998. URL:

https://assets.publishing.service.gov.uk/government/uploads/system/uploads/attachment_data/file /85772/Guidance-for-civil-servants.pdf (дата обращения: 29.10.2018).

${ }^{3}$ The Guardian, 19.11.2015; "Civil service staff numbers", The Institute for Government, 12.09.2018. URL: https://www.instituteforgovernment.org.uk/explainers/civil-service-staffnumbers (дата обращения: 29.10.2018).

4 "Public Bodies 2006", Cabinet Office. URL:

https://assets.publishing.service.gov.uk/government/uploads/system/uploads/attachment_data/file 1266228/PublicBodies2006.pdf (дата обращения: 29.10.2018).

5 "Public Bodies 2016", Cabinet Office. URL: https://assets.publishing.service.gov.uk/government/uploads/system/uploads/attachment_data/file 1579603/public_bodies_report_december_2016.pdf (дата обращения: 29.10.2018).

Современная Европа, 2019, №2 
та. Например, если группа интересов стремится получить средства для строительства дороги, ей нужно одновременно лоббировать как Министерство транспорта, которое первоначально принимает решение, так и Дорожное агентство (КВАНГО), которое принимает решение о выделении средств [Zetter, 2008: 110]. Особенность КВАНГО также заключается в том, что данные организации сами могут выступать в роли лоббистов. Будучи тесно связанными с профильными министерствами и службами, их представители обладают прямым доступом к лицам, принимающим решения. В результате, возникает многоуровневый механизм лоббирования, когда группы интересов влияют на КВАНГО, а те, в свою очередь, лоббируют правительственные органы, к которым имеют прямой доступ. Помимо этого, КВАНГО зачастую сами являются встроенными лоббистами, так как уровень их влияния зависит от размера выделяемого им бюджета. В результате возникает парадокс, когда "правительство лоббирует правительство". КВАНГО периодически попадают под сокращение, однако их реальная роль в политическом процессе не снижается.

\section{Кабинет министров и члены парламента}

Гражданская служба остается ключевым объектом влияния, но при этом стратегии групп интересов почти всегда включают в себя работу с парламентариями, так как решение обрастает многочисленными деталями на разных стадиях парламентских дискуссий, слушаний и предоставления дополнительной экспертизы. Наиболее сложными объектами для лоббирования интересов являются члены парламента, формирующие кабинет министров. Закрытость министров определяется их постоянной занятостью, поэтому значительную часть каждодневной работы они делегируют своим советникам. Налаженный контакт с советниками в значительной степени облегчает коммуникацию лоббистов с министрами. Однако, помимо взаимодействия с советниками, есть ряд других методов, позволяющих привлечь внимание министров, которые можно разделить на прямые и косвенные. К прямым методам относятся отправка писем с просьбой о встрече или рассмотрении вопроса, рассылка приглашений для участия в конференциях, прочих публичных или закрытых мероприятиях, а также личные встречи на партийных конференциях, традиционно привлекающих значительное количество лоббистов.

Косвенные методы предполагают работу с рядовыми парламентариями, которые пользуются доверием министров и могут убедить их рассмотреть вопрос либо встретиться с лоббистом. Большинство министров (кроме пэров) являются представителями своих округов, поэтому обычно более активно идут на контакт, если он каким-либо образом касается вопросов, связанных с жизнью округа. Наконец, работа со СМИ и формирование общественного мнения являются ключевым способом косвенного влияния, которое, при должном раскладе, способно привлечь внимание министров. Обычно министры лично встречаются с представителями тех групп интересов, которые определяют стратегические векторы развития. Например, как показало исследование Global Justice Now и Corporate Europe Observatory, 91\% встреч министра торговли и $70 \%$ встреч министра по вопросам выхода Великобритании из ЕС в 2016-2017 гг. состоялись с представителями крупного бизнеса ${ }^{1}$.

1 "Big Business Brexit: Corporate interests still dominate Brexit and trade lobbying", Corporate Europe Observatory, 13.12.2017. URL: https://corporateeurope.org/power-lobbies/2017/12/big-businessbrexit-corporate-interests-still-dominate-brexit-and-trade (дата обращения: 29.10.2018).

Современная Европа, 2019, №2 
Значительные возможности для влияния групп интересов заложены в процедурах согласования и принятия решений в парламенте. После того, как законопроект поступает в парламент, его сначала рассматривает Палата общин. Важным объектом лоббизма в Палате общин являются отборочные комитеты, которые создаются для поддержки профильных департаментов в исполнительной ветви. Влияние отборочных комитетов заключается в том, что они аккумулируют, обрабатывают и представляют экспертную информацию, в том числе со стороны внешних интересов, которая потом используется для дополнения или изменения законопроектов. Помимо этого, отборочные комитеты готовят специальные доклады, которые затем пользуются пристальным вниманием в профессиональных сообществах и СМИ.

При рассмотрении законопроектов, группы интересов также стремятся оказывать влияние на рядовых парламентариев, не являющихся членами кабинета. Тем не менее в условиях обычно строгой партийной дисциплины такое влияние имеет пределы возможностей и касается лишь тактических изменений будущих законов. К тому же, как показало исследование, проведенное П. Бернхагеном, лишь в незначительном количестве случаев лоббисты добиваются успеха, когда их цели вступают в противоречие с политикой правящей партии [Bernhagen, 2013: 35-37]. Во время слушаний и постановки вопросов в повестке дня важную роль играют представители оппозиционной партии, которые охотно задают вопросы, идущие вразрез с позицией правящей партии. Оппозиционная партия не имеет возможности прямо участвовать в процессе принятия решений, однако её представители способны вносить предложения для обсуждения, критиковать решения, принимаемые правящей партией и оказывать существенное влияние на общественное мнение и СМИ.

После того, как законопроект проходит через Палату общин, его рассматривает Палата лордов. С точки зрения лоббизма взаимодействие с Палатой лордов является важным и, по сравнению с нижней палатой, менее обременительным способом влияния на принимаемые решения. Это вызвано более простыми процедурами предоставления экспертной информации, большей открытостью пэров, отсутствием партийного большинства. Верхняя палата обладает ограниченным правом вето при принятии законопроектов, но она может вносить многочисленные поправки и отправлять законопроект на дополнительную проработку в Палате общин. Так как Палата лордов напрямую не зависит от правительства, она гораздо чаще противостоит решениям, исходящим от политического руководства. Например, между 1999 и 2005 гг. пэры отправили на доработку 283 законопроекта из 873, то есть 35\% [Russel, Sciara, 2007: 301]. Даже пэры, принадлежащие к партии, побеждающей на выборах в Палату общин, часто не поддерживают инициативы правительства. Исследования показывают, что партийная принадлежность мало влияет на исход дискуссии и голосования в Палате лордов [Russel, Sciara, 2007: 319-320]. Примерно половина законопроектов, возвращаемых Палатой лордов в Палату общин, действительно подвергаются пересмотру, хотя положительный для групп интересов исход в верхней палате требует от лоббистов продолжения работы с членами нижней палаты [Zetter, 2008: 199].

Помимо участия в парламентских процедурах, группы интересов могут иметь рычаг влияния, если они вовлечены в финансирование политических партий. Финансирование партий регулирует закон "О политических партиях, выборах и референдумах" от 2000 г. и находится под постоянным мониторингом независимой Из-

Современная Европа, 2019, №2 
бирательной комиссии. Согласно данным Избирательной комиссии, в 2017 г., когда проводились парламентские выборы, три основные партии получили пожертвования в размере 93,5 млн ф. ст ${ }^{1}$. Основную часть составили индивидуальные пожертвования (44,6 млн), частные компании (17,2 млн), профсоюзы (16,9 млн) и публичные фонды (11,1 млн). 2017 г. подтвердил тенденцию поддержки крупным бизнесом Консервативной партии, в то время как лейбористы возвращаются к привычной финансовой зависимости от профсоюзов и членских взносов. Если в шестинедельный предвыборный период в 2005 и 2010 г. Лейбористская партия получала соответственно $41 \%$ и $64 \%$ финансовой поддержки от профсоюзов, то в 2017 г. этот показатель за аналогичный период составил 96\%. Консерваторы, в свою очередь, за весь 2017 г. на 37\% превысили показатель поддержки со стороны корпоративного сектора по сравнению с 2010 г. [Fisher, 2018: 181-182]. Данная тенденция связана с тем, что бизнес возвращается к доблэровскому негативному восприятию Лейбористской партии и всё теснее взаимодействует с консерваторами, в то время как усиление позиций Дж. Корбина, напротив, привлекает все больше поддержки со стороны профсоюзов и рядовых членов.

Тем не менее механизм финансирования партий нельзя назвать прозрачным. Во-первых, не существует верхних границ для пожертвований в партийные фонды. Последний раз предложение об ограничении влияния “больших денег” и установлении верхней планки в размере 5 тыс. ф. ст. было внесено лейбористами в 2012 2013 гг., однако правительство консерваторов его не поддержало‥ Во-вторых, существует практически ничем не ограниченная практика внутреннего финансирования политических партий, особенно распространённая среди пэров. Согласно Transparency International, общий размер пожертвований в партийные фонды со стороны членов Палаты лордов за 2001-2014 гг. составил 39 млн ф. ст. [DavidBarrett, 2015: 17]. В 2011-2014 г. 40\% всех пожертвований Партии либеральных демократов были сделаны тремя бизнесменами, которые затем стали пэрами ${ }^{3}$. Это был не первый случай: в 2006-2007 гг. лейбористы были замешаны в ещё более крупном скандале “Деньги в обмен на титулы”, хотя продажа титулов запрещена законом от 1925 г. В-третьих, существуют скрытые механизмы финансирования, например через различные членские клубы, которые имеют возможность пропускать финансирование от анонимных членов, затем получающих возможность общаться с высокопоставленными политиками, приглашёнными на закрытые званые ужины и встречи. В 2012-2014 гг. Клуб лидеров организовал 72 встречи своих членов с Д. Кэмероном и его министрами в обмен на минимальное пожертвование в размере 50 тысяч фунтов [David-Barrett, 2015: 17].

\section{Проблемы регулирования}

Институт лоббизма в Великобритании имеет длительную историю становления, однако значительная его часть всё ещё находится в тени. Формализация лоббизма впервые оказалась в повестке руководства страны при Дж. Мейджоре. В 1994 г.

${ }^{1}$ The Electoral Commission. URL: https://www.electoralcommission.org.uk/ (дата обращения: 29.10.2018)

${ }^{2}$ The Guardian, 10.07.2013.

${ }^{3}$ The Daily Mail, 15.06.2014.

Современная Европа, 2019, №2 
правительство консерваторов инициировало в Палате общин создание Комитета по стандартам публичной сферы, известного как Комитет Нолана. Это стало ответом на самый громкий на тот момент лоббистский скандал “деньги в обмен на вопросы". Доклады комитета легли в основу внедрения новых принципов лоббистской деятельности - честности, чистоты, открытости, объективности, альтруизма, подотчётности.

Впрочем, Комитет Нолана изначально фокусировался не столько на лоббистах и контроле над ними, сколько на самих политиках. В первом докладе Комитета Нолана говорилось, что “снижение доверия к финансовой честности членов парламента совпало с ростом количества парламентариев, предоставляющих консалтинговые услуги, напрямую относящиеся к их парламентской роли"2. По сути, речь шла о конфликте интересов, возникавшем у тех членов парламента, которые одновременно занимали руководящие посты или должности советников в частном секторе, то есть были внутренними лоббистами. В то же время в докладе была сделана оговорка, что Палата общин будет менее эффективной, если запретить политикам заниматься внешней деятельностью, так как это снизит уровень их информированности при принятии решений.

Двоякая позиция относительно конфликта интересов сохраняется по сей день, хотя за последние четверть века были значительно расширены кодексы поведения как в обеих палатах парламента, так в региональных собраниях. В частности, члены Палаты общин должны декларировать в Реестре интересов оплачиваемые должности, которые они занимают в частных и публичных организациях, оплачиваемую работу, в том числе консультационные услуги, имена клиентов, которым предоставляются какие-либо услуги, пожертвования и прочие формы поддержки со стороны частных и публичных организаций, а также получаемые подарки, рабочие поездки, собственность, ценные бумаги и пр. Публичные реестры периодически обновляются, тем не менее проблема конфликта интересов остаётся нерешённой. Примерно каждый пятый член Палаты общин имеет регулярную оплачиваемую работу за пределами парламента, но ничто не мешает им инициировать парламентские процедуры и предлагать поправки к законам в интересах представляемых ими организаций ${ }^{3}$.

Более того, министры на национальном и региональном уровнях сами определяют, что подпадает под конфликт интересов, а что нет. В этом они следуют весьма размытой формулировке, прописанной в кодексах Палаты общин североирландской и уэльской ассамблей, что любые конфликты интересов должны решаться в пользу общественных интересов ${ }^{4}$. Попытки изменить кодексы поведения пока не увенча-

\footnotetext{
${ }^{1}$ Расследование The Guardian показало, что члены от Консервативной партии готовы были за деньги задавать вопросы на парламентских слушаниях в интересах миллиардера Мохаммеда Аль-Файеда.

${ }^{2}$ Summary of the Nolan Committee's First Report on Standards in Public Life, 1995. URL: https://assets.publishing.service.gov.uk/government/uploads/system/uploads/attachment_data/file 1336840/1stInquiry_Summary.pdf (дата обращения: 29.10.2018).

${ }^{3}$ The Guardian, 03.07.2018.

4 "The Code of Conduct for Members of Parliament". URL: https://publications.parliament.uk /pa/cm201012/cmcode/1885/188502.htm (дата обращения: 29.10.2018).

Современная Европа, 2019, №2
} 
лись успехом, так как подобные рассмотрения затягиваются, а ряд парламентариев, особенно консерваторов, считают, что любые более жесткие рамки поведения ограничат их свободу при принятии решений. Что касается гражданской службы, то её представители вовсе не должны отчитываться о внешних интересах. Их деятельность основана на принципах честности и объективности, однако никаких чётких правил взаимодействия с группами интересов в их кодексах поведения не прописано ${ }^{1}$.

Вторым вектором регулирования является раскрытие информации о лоббистах и целях их взаимодействия с официальными лицами. После обнародованных докладов Комитета Нолана было решено перейти к саморегулированию отрасли, а лоббистские фирмы учредили Ассоциацию профессиональных политических консультантов (АППК). Она призвала своих членов принять кодексы поведения, сделать публичный реестр компаний-членов, а также публиковать данные о встречах с официальными лицами. В 2010 г. возник Британский совет по публичным делам (БСПД), объединивший три крупнейших ассоциации политических консультантов, их членские списки и реестры контактов, который просуществовал до 2015 г. и был в итоге ликвидирован как не достигший своих целей. Саморегулирование оставляло множество пробелов, ведь ни одна компания, предоставляющая лоббистские услуги, не обязана становиться членом каких-либо объединений, а единый стандарт кодексов поведения так и не был разработан, что привело к чрезмерной размытости отдельных его разновидностей [Keeling et al., 2018: 128].

После признания провала саморегулирования на фоне неутихающих скандалов правительство в 2014 г. приняло закон "О прозрачности лоббирования, непартийных кампаниях и управлении профсоюзами”, в котором впервые в британской истории прописан порядок официальной регистрации лоббистов. Тем не менее новый закон, а также последовавший за ним в 2015 г. независимый реестр лоббистов в недостаточной мере способствовали формализации и большей прозрачности лоббистской деятельности. При удивительно быстром принятии закона, Консервативная партия проигнорировала значительную часть предложений профессиональных лоббистов, оппозиционных политиков, экспертов и самих групп интересов. В частности, закон распространяется только на лоббистов-консультантов, но не на внутренних лоббистов, хотя большая часть влияния осуществляется именно посредством сотрудников правительства или парламента, представляющих внешние интересы. Более того, регистрации подлежат только консалтинговые фирмы, а не её работники, которые непосредственно вступают в контакт с официальными лицами. Помимо этого, регистрации не подлежат лица, чьей основной деятельностью не является лоббизм, хотя чёткого критерия выделения профессиональных лоббистов не дано. По сути, реестр лоббистов предоставляет даже меньше информации по сравнению с той, что по сей день доступна в АППК. По словам С. Килинга и коллег, британский закон о лоббизме не раскрывает большую часть реального лоббизма в органах власти и регулирует лишь малую часть индустрии [Keeling et al., 2018: 136]. По мнению наблюдателей, существующий реестр раскрывает не более 5\%

1 Civil Service management code. URL: https://www.gov.uk/government/publications/civilservants-terms-and-conditions (дата обращения: 29.10.2018).

Современная Европа, 2019, №2 
лоббистских контактов ${ }^{1}$. Ни саморегулирование, ни государственное регулирование не раскрывают финансовой составляющей лоббизма. По словам Ал.А. Громыко, регулирование лоббизма в Великобритании оставляет немало лазеек, “оффшорных территорий”, двусмысленных толкований, превращающих лоббизм в коррупцию [Громыко, 2010:119-120]. Тем не менее, как считают Т. Моррис и С. Голдсуорси, дальнейшие скандалы неизбежны, а это приведет к пересмотрам и дополнениям законодательства [Morris, Goldsworthy, 2016]. Есть основания считать, что данный закон является лишь первым шагом на пути дальнейшего регулирования лоббизма.

В глазах общественного мнения лоббизм связан в первую очередь со скандалами, однако взаимодействие групп интересов с органами власти становится всё более важной составляющей политического процесса. Увеличение количества как лоббистов-консультантов, так и встроенных лоббистов, а также разнообразие точек входа в процесс принятия решений, методов и стратегий влияния на разных уровнях власти позволяет утверждать, что британская индустрия лоббизма находится в стадии динамичного роста. Природа данного процесса, как впервые было отмечено в докладах Комитета Нолана, носит двоякий характер. С одной стороны, лоббизм является взаимовыгодной деятельностью как для групп интересов и представляющих их лоббистов, так и для политиков и чиновников, для которых группы интересов являются ценным источником экспертных знаний и ресурсов. С другой стороны, закрытость мира лоббизма, постоянные скандалы, недоверие к лоббизму со стороны общества и растущие требования большей прозрачности вынуждают индустрию искать способы дальнейшей легитимизации. Постепенная профессионализация лоббизма, увеличивающиеся масштабы дискуссии о допустимых пределах влияния и правилах лоббистской деятельности в обществе, политической среде и экспертных кругах говорят о том, что лоббизм в Великобритании более не может оставаться уделом избранных, и неизбежно будет двигаться в сторону большей прозрачности и инклюзивности.

\section{Список литературы}

Громыко Ал.А., Ананьева Е.В. (ред.) (2014) Дилеммы Британии, Весь мир, Москва, Россия, 480 с.

Громыко Ал.А. (2010) Коррупция в высших эшелонах власти Великобритании, ОбозревательObserver, №10, c. 117-128.

Ильичева Л.Е. (2014) Лоббизм в Великобритании, Служба PR, №5, с. 49-54.

Ходырев А.А. (2013) Правовой статус британских публичных корпораций в эпоху “непрозрачного административного государства", Журнал зарубежного законодательства и сравнительного правоведения, №3, с. 526-531.

\section{References}

Bernhagen P. (2013) When do politicians listen to lobbyists (and who benefits when they do)?, European Journal of Political Research, 2013, vol. 52, issue 1, pp. 20-43.

David-Barrett E. (2015) Lifting the Lid on Lobbying. The Hidden Exercise of Power and Influence in the $U K$, Transparency International, $76 \mathrm{p}$.

${ }^{1}$ The Guardian, 21.09.2015. 
Fisher J. (2018) Party Finance, Parliamentary Affairs, no. 71, pp. 171-188.

Gromyko Al.A., Anan'eva E.V. (eds.) (2014) Dilemmy Britanii, Ves' mir, Moscow, Russia, 480 p.

Gromyko Al.A. (2010) Korruptsiya v vysshikh ehshelonakh vlasti Velikobritanii, Obozrevatel'Observer, №10, pp. 117-128.

Heywood A. (2008) Essentials of UK Politics, Palgrave Macmillan, UK, 328 p.

Holden C., Hawkins B. (2012) "Whisky gloss": The alcohol industry, devolution and policy communities in Scotland, Public Policy and Administration, 28(3), pp. 252-273.

Il'icheva L.E. (2014) Lobbizm v Velikobritanii, Sluzhba PR, №5, pp. 49-54.

Jones B., Norton P. (2014) Politics UK, Routledge, UK, 640 p.

Keeling S., Feeney S., Hogan J. (2017) Transparency! Transparency? Comparing the new lobbying legislation in Ireland and the UK, Interest Groups and Advocacy, 6, pp. 121-142.

Khodyrev A.A. (2013) Pravovoj status britanskikh publichnykh korporatsij v ehpokhu neprozrachnogo administrativnogo gosudarstva, Zhurnal zarubezhnogo zakonodatel'stva i sravnitel'nogo pravovedeniya, №3, pp. 526-531.

McGrath C. (2018) British Lobbying in Newspaper and Parliamentary Discourse, 1800-1950, Parliamentary History, vol. 37, pt. 2, pp. 226-249.

Morris T., Goldsworthy S. (2016) PR Today: The authorities guide to public relations, 2 nd ed, Palgrave, Basingstoke, UK, $370 \mathrm{p}$.

Russell M., Sciara M. (2007) Why Does the Government get Defeated in the House of Lords?: The Lords, the Party System and British Politics, British Politics, vol. 2, issue 3, pp. 299-322.

Weiler F., Brandli M. (2015) Inside versus outside lobbying: How the institutional framework shapes the lobbying behaviour of interest groups, European Journal of Political Research, vol. 54, issue 4, pp. 745-766.

White J., L'Etang J., Moss D., (2009) "The United Kingdom: Advances in Practice in a Restless Kingdom”, in: Sriramesh K., Vercic D. (eds.) The Global Public Relations Handbook, Routledge, UK, pp. 381406.

Wootton G. (1975) Pressure Groups in Britain 1720-1970: An Essay in Interpretation with Original Documents, Hamden, 400 p.

Zetter L. (2008) Lobbying - the art of political persuasion, Harriman House, 454 p.

\section{Trends in Lobbying Development in Britain}

Author: Kanevskiy P., Candidate of Science (Politics), Associate Professor at the Department of Political Science and Sociology of Political Processes, Lomonosov Moscow State University. Address: 1, Leninskie Gory, Moscow, Russia, 119991. E-mail: kanevskiy@ socio.msu.ru

Abstract. The article is dedicated to the complex analysis of lobbying in the United Kingdom during the late XX - early XXI centuries. Lobbying is an integral element of UK politics, at the same time we still have insufficient knowledge about interest groups. Interaction between interest groups and the government is becoming more diverse and multileveled. The author aims to examine the lobbying mechanism in the UK. The author also analyzes the ways which interest groups and lobbyists use to interact with civil service, QUANGOs, political parties and the parliament, the cabinet of ministers and the prime minister. The article also touches upon the issues concerning the evolution and the current state of lobbying regulation. The author comes to conclusion that tendencies of lobbying development have a twofold nature. On the one hand, interest groups and officials are keen to preserve the mechanism of interaction. For the parties and the government that means receiving information and resources. Interest groups would like to preserve the traditions of openness and to have stable relations with the decision makers. On the other hand, permanent scandals, low level of public trust towards lobbyists and falling legitimacy of the parties force politicians and lobbyists to look for ways of regulation the lobbying environment. Despite the revision of codes of conduct and adoption of the first lobbying law in history, most lobbying relations stay in shadow, because many politicians are concerned that it could limit their freedom in decision making. Hence, the development of lobbying in the UK depends on the balance between preserving the freedom of cooperation between interest groups and the government and transparency of the political process.

Key words: lobbying, interest groups, politics in the UK, civil service, British parliament.

DOI: http://dx.doi.org/10.15211/soveurope220196272

Современная Европа, 2019, №2 